\title{
Pectinsubstanzen und deren Metamorphose während des Vegetationsprocesses.
}

Ueber die Zusammensetzung des Fleisches der Früchte und saftiger Wurzeln, so wie uiber die Veränderungen, welche während des Reifens der Früchte vor sich gehen, hat E. F r é $m$ y umfassende Untersuchungen angestellt. Seine dabei gewonnenen Resultate zeigen in vielen wesentlichen Puncten Abweichungen von den Ergebnissen der Analysen anderer Chemiker über diesen Körper.

Das Ergebniss von Frémy's Untersuchungen lässt sich in folgenden Sätzen zusammenfassen.

1) In dem Zellgewebe der Pflanzen, besonders in dem der unreifen fleischigen Früchte $(z$. B. der Aepfel, Birnen, Pflaumen, Stachelbeeren) und der fleischigen Wurzein (z. B. der Möhren und Ruiben) findet sich neben der in Wasser und verdünnten Säuren unlöslichen Cellulose ein anderer, zwar in Wasser und kalten verdünnten Säuren unlöslicher, aber durch erwärmte verdiunnte Säuren löslich werdender Körper, die Pectose.

2) Die Pectose konnte bis jetzt nicht von der Cellalose getrennt werden. Durch Einwirkung von verdiunnten Säuren erleidet sie eine Modification und verwandelt sich in Pectin, d. $h$. in einen gummiahnlichen Körper, der sich in kaltem Wasser za einer klebrigen neutralen Flüssigkeit löst. Die wässrige Lösung wird durch neutrales essigsaures Bleioxyd nicht verändert.

3) Beim Kochen mit Wasser geht das Pectin in Parapectin über. Die Lösung ist noch neutral, wird aber jetzt durch neutrales essigsaures Bleioxyd gefällt.

4) Unter dem Einflusse verdünnter Säure verwandelt sich das Parapectin in einen Lackmus röthenden, durch Chlorbaryum lällbaren Körper, den Frémy Metapectin oder melapectinige $S$ äure nennt.

5) Peclin, Parapectin und metapectinige Säure (Metapectin) sind farblose, unkrystallisirbare, in kaltem und heissem Wasser zu klebrigen Flüssigkeiten Jösliche Körper. Ihre wässerigen Lösungen gerinnen beim Vermischen mit Alkohol zu Gallerte.

Mit Säuren, z. B. mit Schwefelsäure oder Oxalsäure, geben sie im Wasser lösliche, unkryslallisirbare Verbindungen, die durch Alkohol aus der wässrigen Lösung in Form von Gallertflocken abgeschieden werden. biese Verbindungen sind wenig constant und schon durch Auswaschen zerlegbar.

fi) Nehen Cellulose und Pectose befindet sich im Zell- 
gewebe oder im Safte fleischiger Früchte und fleischiger Wurzeln ein Körper, welcher die Eigenschaft besitzt, in Berührung mil Peclinlösung aus dem Pectin mehre gallertartige in kaltem Wasser unlösliche Säuren zu erzeugen. Fre m y nennt diesen fermentartig wirkenden Körper P e ctase und die Umsetzung des Pectins in zwei isomere Säuren, in Pectosinsäure und Pectinsäure, durch dieses Ferment Pectingährung. Sie kann der Milchsäuregährung an die Seile gesetzt werden, weil eben so, wie bei der Umwandlung des Zuckers in Milchsäure, bei dem Uebergange des Pectins in Pectosinsäure und Pectinsäure, weder Sauerstoffabsorption, noch Gasentwicklung statt findet und die isomeren Gährungsproducte saurer Natur sind. Die Pectase kommt in den Pflanzen als lösliche und als unlöslich e Modification vor; erstere z. B. in dem frisch gepressten Möhrensafte, aus welchem sie durch Weingeist gefällt werden kann; letztere in den Aepfeln.

7) Das erste Product der Einwirkung von Pectase auf Pectin ist Peclosinsäure. Diese ist gallertartig, unlöslich in kaltem, völlig löslich in heissem Wasser. Die heiss gesältigte Lösung erstarrt beim Erkalten zu einer Gallerte. Durch längere Einwirkung der Pectase auf Pectin oder Pectosinsäure entsteht $\mathrm{Pectinsäu} \mathrm{re,} \mathrm{ein} \mathrm{gallert-}$ artiger, in kaltem und heissem Wasser unlöslicher, in Alkalien leicht löslicher Körper.

8) Bei Einwirkung von ätzendem und kohlensaurem Kali oder Natron, von Baryt, Kalk und Strontian auf Pectinlösung entstehen ebenfalls Pectosinsäure und Pectinsäure.

9) Pectinsäure löst sich in Neutralsalzen mit alkalischer Basis, besonders in Ammoniaksalzen mit organischen Säuren in beträchtlicher Menge auf und bildet sauer reagirende, in heissem Wasser leicht lösliche, beim Erkalten gallertartig sich auscheidende Doppelverbindungen. Alkohol schlägt dieselben aus ibrer wässerigen Lösung gallertartig nieder.

10) Mehrere Stunden mit Wasser gekocht, verwandelt sich die Pectinsäure in Parapectinsäure, welche in Wasser leicht löslich und unkrystallisirbar ist und deutlich sauer reagirt. Bei längerer Einwirkung des siedenden Wassers geht Pectinsäure und Parapectinsäure in Metapectinsäure über. Letztere ist unkrystallisirbar, leicht in Wasser löslich, von starker saurer Reaction und eine der Aepfelsäure sebr nahe stehende Säure. Von der Parapectinsäure unterscheidet sie sich dadurch, dass sie 
mit Baryt eine in Wasser lösliche Verbindung liefert, während Parapectinsäure durch Barytwasser gefallt wird.

11) Parapectinsäure und Metapectinsäure entstehen ferner bei längerer Einwirkung von Säuren, Alkalien oder Pectase auf Pectin und Peclinsảure. Beide Säuren besitzen die Eigenschaft, beim Kochen mit weinsaurem KupferoxydKali Kupleroxydul zu reduciren. Da sie diese Eigenschaft mit den Zuckerarten theilen (und mit dem Laclucin und der Laclucasäure (Archiv d. Pham. Bd.50. p.133), so können sie Täuschungen veranlassen.

12) Die Pflanzengallerten und Gallertsäuren bis auf $200^{\circ} \mathrm{C}$. erhitzt, entwickeln Wasser und Kohlensäure und hinterlassen einen schwarzen nicht flüchtigen in Wasser unlöslichen Rückstand, der in Alkalien mit brauner Farbe sich löst und von Frémy Pyropectinsäure genannt wird.

13) Die gallertartigen Pflanzensubstanzen besitzen meistens die Natur einer Säure. Ihre Sättigungscapacität vergrössert sich in dem Maasse, als sie sich von der Pectose entfernen.

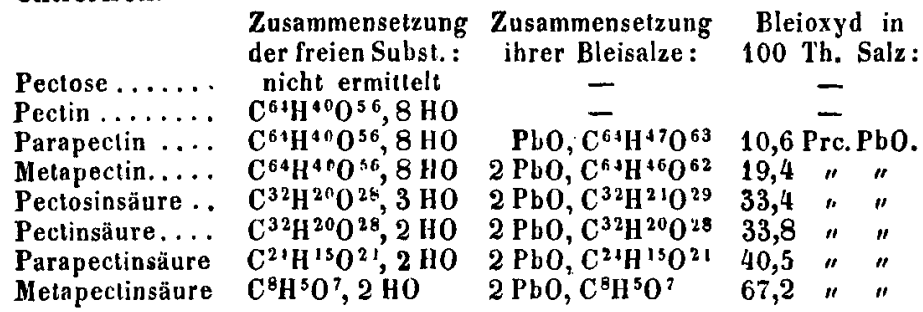

Bei Pectin. Parapectin, Metapectin und Pectosinsäure sind bei den Formeln in der zweiten Spalte die Wasseratome durch ein Kornma nur deshalb getrennt worden, um zu zeigen, dass nach Abzug dieser Wasseratome ein mil der Metapectinsäure isomerer Körper bleibt.

14. Beim Kochen unreifer Früchte wird die in denselben vorhandene Pectose durch Einwirkung der gleichzeitig vorhandenen Aepfelsäure, Citronensäure u. a. Säuren in Pectin verwandelt. Durch die schleimige Beschaffenheil des Pectins wird die freie Säure verdeckt.

15) Die Pflanzen - oder Fruchtgelées entstehen: a) durch Einwirkung der Pectase auf Pectin und Umwandlung desselben in gallertartige unlösliche Pectosinsäure und Pectinsäure; b) durch Verbindung der an und für sich in heissem Wasser unlöslichen Pectinsäure mit den organischsauren Salzen der Früchte zu Doppelsalzen, welche in 
heissem Wasser sich leicht lösen, aber beim Erkalten sich gallertartig wieder abscheiden.

16) Die Pectose ertheilt den unreifen Früchten ihre Härte. Während des Reifens verwandelt sich die Pectose (nicht die Cellulose) nach und nach in lösliches Pectin, Parapectin, Metapectin und lösliche Metapectinsäure. Die Früchte erlangen durch Abnahme der Pectose und Zunahme der löslichen Verbindungen eine immer grössere Weichheit. Wärme beschleunigt die Umwandlung der Pectose in die ubrigen Pectinsubstanzen.

In den reifen Früchten findet sich vorzugsweise Pectin und Parapectin. In den teigigen Früchten sind metapectinsaurer Kalk und metapectinsaures Kali vorhanden.

Ueberhaupt gehört die Metapectinsäure gleich der Aepfelsäure zu den am meisten verbreiteten Pflanzensäuren. Sie findet sich z. B. im Rohrzuckersyrup und Runkelrubensyrup. (Annal.de Chim.et de Phys. Tom.24.p.5-58.)

\section{H. Ludwiy.}

\section{Stärke aus Rosskastanien.}

Nach den neueren Erfahrungen von Belloc haben die vielfach vorgeschlagenen Alkalien gar nicht, wie man geglaubt hat, die Fähigkeit, den bittern Stoff aus der Rosskastanienstärke zu entfernen; wohl aber erreicht man diesen Zweck vollständig durch wiederholtes Ausziehen der geriebenen Früchte mit blossem Wasser. Belloc hat auf diese Weise aus den Früchten der Rosskastanien Stärke dargestellt, welche eine vollkommen weisse Farbe besass und ganz geschmacklos war. Suppen und Gebäck, welche man mittelst dieser Stärke bereitete, wurde wohlschmeckender gefunden als bei Anwendung von Kartoffelstärkemehl.

100 Theile frische, zerriebene Rosskastanien gaben 19 - 21 Proc. trockne Stärke, während Kartoffeln, auf gleiche Weise mit denselben (allerdings unvollkommenen) Apparaten zerkleinert und ausgewaschen, nur 11,7 Proc. trockne Stärke lieferten. (Compt.rend. 1849. - Polytechn. Centrbl. 1849. No. 7.) $B$.

\section{Analyse der Asche eines Heuschobers.}

Im Herbste des vorigen Jahrs wurde auf einer gräflich Wenckheim'schen Herrschaft im Banal ein nach Angabe aus mehr als 2000 Centnern bestehender Heuscho- 